\title{
Hydrodinamic Processes Control System for Wastewater Using Artificial Intelligence Techniques
}

\author{
Anamaria-Cătălina Nițu
}

\begin{abstract}
In this study, it is presented a multicriterial approach of the automatic management techniques of industrial installations using wastewater. This has an extremely positive effect on the economical results of the entire irrigation and wastewater equipment. Choosing the automatic management by a neural networks system is the result of several stages of analysis, modelling and simulation of hydrodynamic processes that take place within the wastewater installation on each equipment and in its integrity. The study exposes an analysis and offers a solution of automatic management of the installation of irrigation using wastewater.
\end{abstract}

Keywords - hydrodinamic processes, wastewater, neural networks system.

\section{INTRODUCTION}

The implementation of a command and automatic control system of the hydrodynamic processes that appear in the transport and distribution of wastewater installation has as a main goal the efficiency of exploitation by:

- ensuring hydraulic conditions that are necessary for the running,

- perfectioning the functioning power of the hydraulic installation,

- achieving and maintaining the water quality parameters through controlled dilution of wastewater.

Wastewater properties after decantation in the physical stage are specified in table 1. They will change after the dilution with conventionally clear water.

Table. 1. Wastewater properties

\begin{tabular}{|c|c|c|c|}
\hline Nr. crt. & Characteristic & M.U. & Field of variation \\
\hline 1 & $\mathrm{pH}$ & - & $6,8 \ldots 8,0$ \\
\hline 2 & Total suspensions & $\mathrm{mg} / \mathrm{l}$ & $1900 \ldots 2100$ \\
\hline 3 & Fixed residue & $\mathrm{mg} / \mathrm{l}$ & $1500 \ldots 3250$ \\
\hline 4 & Total nitrogen & $\mathrm{mg} / \mathrm{l}$ & $270 \ldots 620$ \\
\hline 5 & Total phosphorus & $\mathrm{mg} / \mathrm{l}$ & $25 \ldots 95$ \\
\hline 6 & Total potassium & $\mathrm{mg} / \mathrm{l}$ & $180 \ldots 260$ \\
\hline
\end{tabular}

Artificial intelligence is defined as an interdisciplinary field with objectives: modeling, algorithmization and implementation of specific human behavior within technical systems. 
Conceptually, artificial intelligence is defined on the basis attributes considered essential for an intelligent system as follows: functional autonomy, self-diagnostics, selforganization, decision making ability, optimality.

A first feature of artificial intelligence is that it always is implemented by man through technical means using software tools.

Analyzing artificial intelligence techniques based on neural networks systems were modeled hydrodynamic processes of irrigation, using modules such nonlinear NARX (Nonlinear AutoRegressive eXogenous with input).

The main classes of models considered are the type of language or Takagy-Sygeno. We have developed a modeling program steps for a given process, from design to simulation models and their validation using Matlab programming environment. Numerical simulation of the process was performed both for varying input size and the variation of size of disturbance.

\section{EXPERIMENT DESCRIPTION}

Modeling of hydrodynamic processes using networks neuronal, involves going through certain stages.

First choose a model defined by structure and rule of associated learning. In this case we have some knowledge about the system that needs to be modeled and that directs us to an ARX type model. After the choice the neural model follows the network training step based on a training data set obtained by measurements on the real system.

The training process is completed when the criterion of performance adopted. That structure, defined by a minimum number of layers, is considered optimal and the minimum number of neurons per layer for which the validation criterion has the lowest value.

The input layer always has a number of units equal to the sum of ng + no $+d$, where $\mathrm{ng}$ is the number of delays from the counter, no is the number of delays from the denominator, and $\mathrm{d}$ is pure delay, expressed in number of sampling periods.

The number of hidden layers and the associated number of neurons on these layers are chosen step by step step by step until the desired network response is achieved in optimal network conditions. If the parallel series structure, represented in figure 1 , is chosen here.

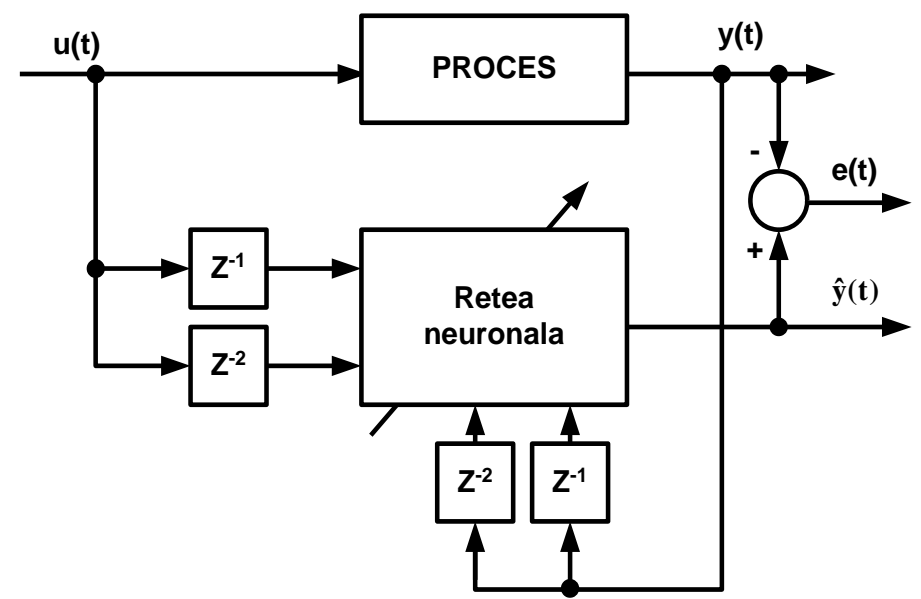

Fig. 1. Process identification model with recurrent neural networks 


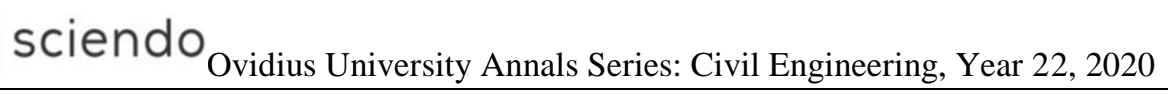

\section{RESULTS AND SIGNIFICANCES}

The training data set is obtained using the "model.m" program.

The data are saved in the file "dataproces" are represented graphically in figure 2.

The next step corresponds to the training of the neural network with the chosen training data.

According to the neural network diagram in figure 1 the network receives at the input a column vector with four components containing the values of the delayed input and output quantities by one and respectively two sampling steps.
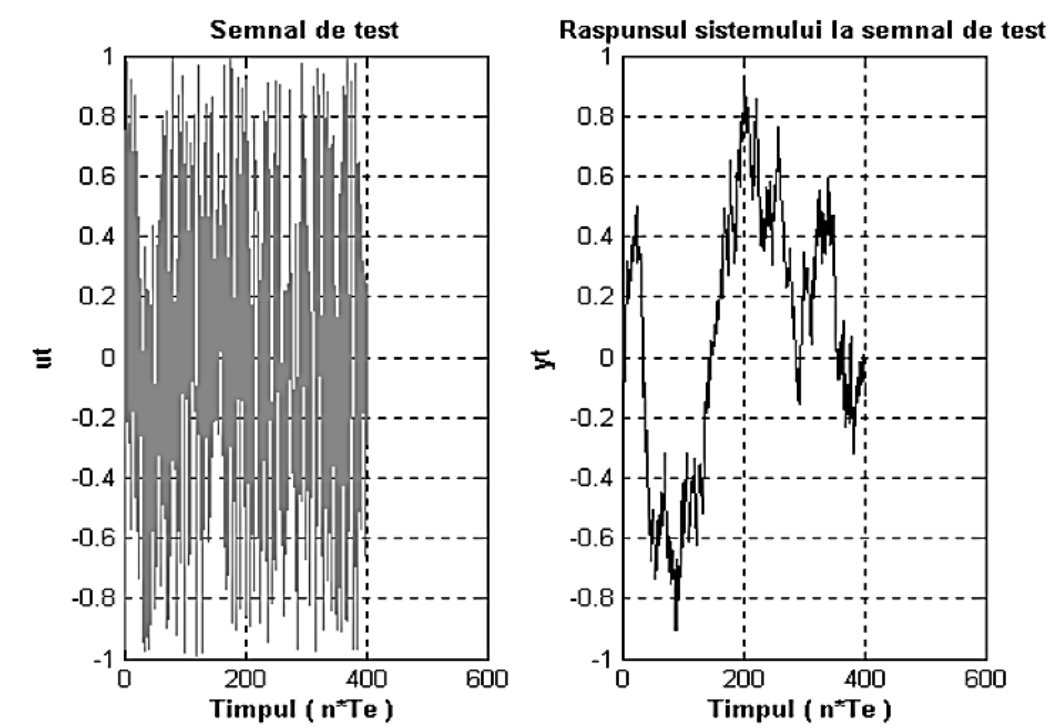

Fig. 2 Graphical representantion of the training dataset

The next step corresponds to the training of the neural network with the chosen training data.

According to the neural network diagram in figure 1 the network receives at the input a column vector with four components containing the values of the delayed input and output quantities by one and respectively two sampling steps.

Therefore the structure of the input vector will be:

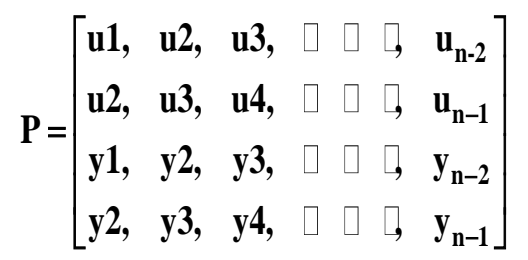

Corresponding to each column vector in this matrix the neural network must provide a value at the output, as shown in the following relation:

$\mathrm{T}=\left[\mathrm{y} 3, \mathrm{y} 4, \quad-\quad-\quad-\mathrm{y}_{\mathrm{n}-1}\right]$ 
After training the network with the "trainbpx" algorithm, the weights are obtained, which are then stored in the "datereţea" file.

The training program itself is called "training.m" which calls the data drive contained in the "dataproces" file. The evolution of the training process is presented in figure 3.
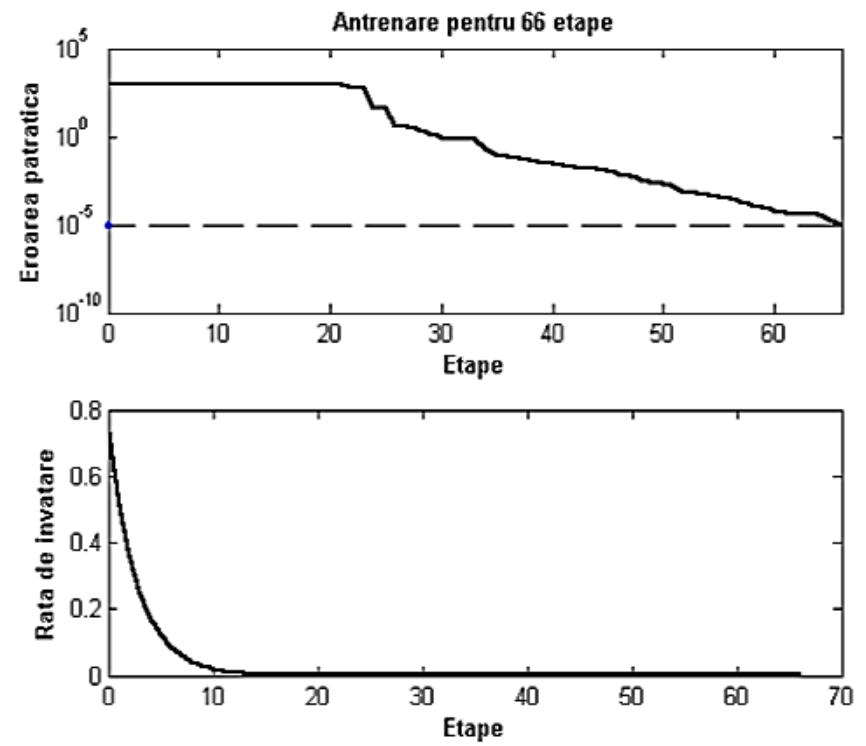

Fig. 3. Evolution of neural network training process

The last stage of model validation is presented in the "validation.m" program which calls the process data file "dataproces" and the parameter data file network "datereţea".

The step signal test is shown in figure 4 :

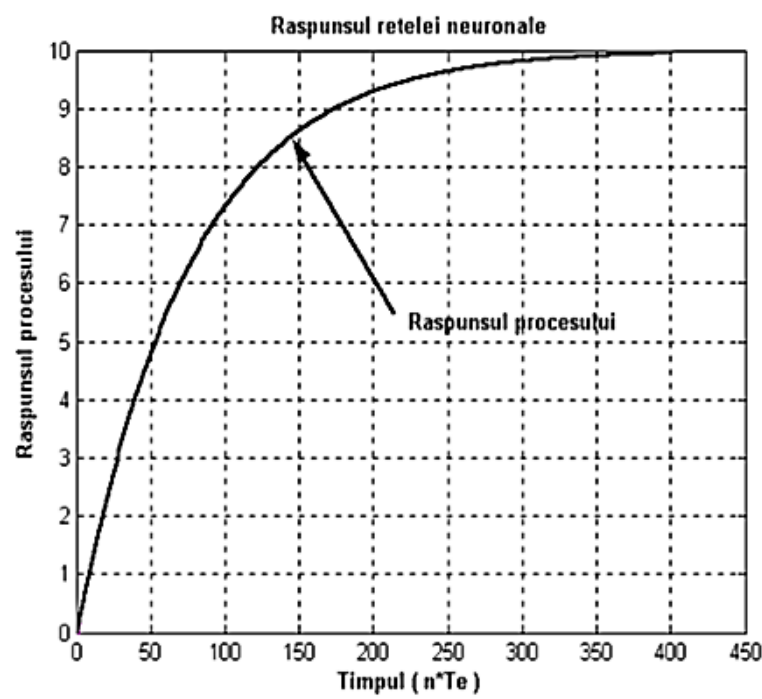

Fig. 4. Validation test signal level 
and the variation of the modeling error is presented in figure 5:

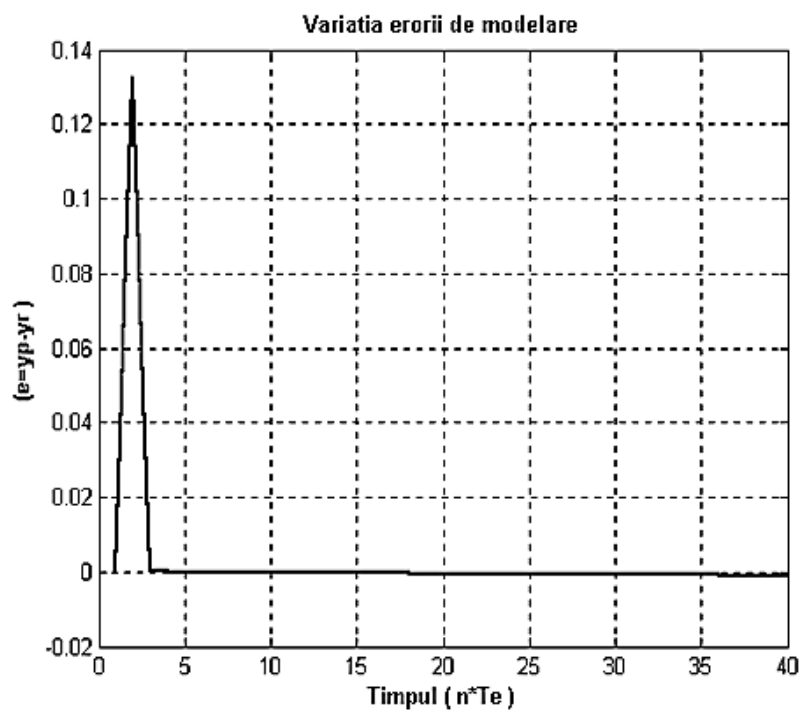

Fig. 5. Variation modelling error

From the analysis of the presented graphs it results that the neural network with the chosen configuration has a good enough behavior to be used in modeling operations, onestep prediction and regulation of the analyzed process.

\section{CONCLUSIONS}

From the analysis of the presented graphs it results that the neural network with the chosen configuration has a good enough behavior to be used in modeling operations, onestep prediction and regulation of the analyzed process.

From the analysis of the previous figures the following conclusions can be underlined:

- cannot be adjusted neural networks regulator in a single step for all range from entry;

- the simulation diagram has a general character and it can be used for every adjustment structure belonging to this category, mentioning that the automatic process has to be appropriately modelled;

- by adjusting the accord parameters of the automatic regulators, a stabile reserve can be ensured;

- the performances of the neural networks system depend on the measures of the accord parameters. By choosing correctly these measures it is possible to maintain the performances within the required limits;

- the implementation of the adjustment structure with neural network regulators allows the distribution of the management and supervising functions for other measures in the process. 


\section{REFERENCES}

[1] Robescu, D., Lanyi, Sz., Robescu, D.L., Verestoy, A.( 2003), Fiabilitatea proceselor,instalaţiilor şi echipamentelor pentru tratarea şi epurarea apelor, Editura tehnică, București

[2] Dordescu M., Trifan A. (2010), Contributions to the hydrodinamic processes control system for multi-phase fluid, Tehnonav 2010 - The $7^{\text {th }}$ International Scientific Conference on Naval, Mechanical, Industrial and Power Engineering - Section III Power Engineering, Editura Ovidius University Press, Constanţa,pp 20-25, 2010

[3] Dordescu M., (2009), Contribuții la controlul automat al proceselor hidrodinamice, Editura MatrixRom, București

[4] Dordescu M.,Bolma A. (2007),"Modeling, Simulation and Regulation of an Industrial Installation Intended for Field Irrigation Using Attenuant Wastewater" -Analele Universităţii „Ovidius” Constanţa anul IX,volumul 1, Simpozionul „Inginerie Civilă 2007”, pp99-106

[5] Roșu L., Maftei C., N., Iordache G., Dordescu M., Buta C., Stănescu M.(2009),” Management issues and strategies in the exploitation of irrigation systems", Universitatea de Științe Agricole și Medicină Veterinară "Ion Ionescu de la Brad" Iași, volumul 52, Seria Horticultură", pp939-944

[6] Dumitrache I., (2005), Ingineria reglării automate, Editura Politehnica Press, Bucureşti [7] DumitracheI., Constantin N., Drăgoicea M., (1999), Rețele neurale. Identificarea și conducerea proceselor, MatrixRom, București

[8]***, Simulink Dynamic System Simulation for MATLAB, user's guide, version 4, MathWorks, Inc, $1990-2000$

\section{Note:}

Anamaria-Cătălina Nițu - Politehnichal University of Bucharest, Bucharest, România, (e-mail: catalina.nitu15@yahoo.ro) 